\title{
Formation of basalt on Mars at 4443 Ma by impact melting of the primordial crust
}

\author{
N. K. JENSEN*, M. M. COSTA, J. N. CONNELly, M. \\ BIZZARRO
}

Centre for Star and Planet Formation, Globe Institute,

University of Copenhagen, Copenhagen, Denmark

(*correspondence: ninna.jensen@sund.ku.dk)

The martian regolith breccia Northwest Africa 7034/7533 and paired meteorites contain a diversity of clast types of both igneous, sedimentary (protobreccia) and impact origin [1,2]. Although it has been suggested that the breccia is dominantly composed of ancient components ( $>4.4 \mathrm{Ga}$ ) [3,4], absolute geochronological studies of individual breccia clasts are both scarce and imprecise due to the analytical difficulties arising from the small sizes of the fragments (typically $<2 \mathrm{~mm}$ in length). As part of a systematic study aimed at providing high-resolution ages of individual igneous breccia clasts, we have, for the first time, conducted full-dissolution $\mathrm{U}-\mathrm{Pb}$ isotope analyses of zircons separated from a single basaltic igneous clast from NWA 7533. From a $\sim 10 \mathrm{mg}$ aliquot of this clast, 21 zircons in the size range 15 to $70 \mu \mathrm{m}$ were separated. The four zircons selected for full-dissolution $\mathrm{U}-\mathrm{Pb}$ isotope analysis record overlapping ${ }^{207} \mathrm{~Pb} /{ }^{206} \mathrm{~Pb}$ dates, consistent with a cogenetic, igneous origin for the zircons and the clast. Recording nearly concordant $\mathrm{U} / \mathrm{Pb}$ ages that define a ${ }^{207} \mathrm{~Pb} /{ }^{206} \mathrm{~Pb}$ date of $4443.6 \pm 1.2 \mathrm{Ma}$, the largest of the four analysed zircons thus constrains the minimum crystallisation age of the basaltic clast. The Lu-Hf isotope systematics of the same zircon reveal that it crystallised from an enriched melt with an initial $\varepsilon \mathrm{Hf}$ value of $-2.0 \pm 0.4$. Together with the combined $\mathrm{U}-\mathrm{Pb}$ and $\mathrm{Lu}-\mathrm{Hf}$ isotope systematics of ancient zircons from NWA 7034/7533 [4,5], the geochronological results for this clast support a model in which the primordial martian crust was formed within $20 \mathrm{Myr}$ of Solar System formation, and that younger $(<4547 \mathrm{Ma})$ Noachian rocks are the crystallisation products of impact melting of this primordial crust. In addition, the petrographical and geochronological results for the basaltic clast require that the reworking of the primordial crust resulted in basaltic melt production, which may reflect the existence of a mafic crustal protolith on Mars at $4443 \mathrm{Ma}$.

[1] Humayun, M. et al. (2013) Nature 503, 513-516. [2] Santos, A. R. et al. (2015) Geochim. Cosmochim. Acta 157, 56-85. [3] Nyquist, L. E. et al. (2016) Meteorit. Planet. Sci. 51, 483-498. [4] Bouvier, L. C. et al. (2018) Nature 558, 586589. [5] Bizzarro, M. et al. (2020) this meeting. 